TI 2019-003/VIII

Tinbergen Institute Discussion Paper
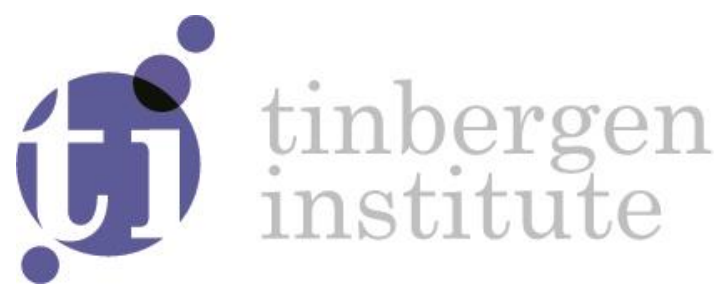

\title{
To join or not to join? The impact of social interactions on local participation decisions
}

Rixt Bijker ${ }^{1}$

Eveline van Leeuwen ${ }^{2}$

Paul (P.R.) Koster

\footnotetext{
${ }^{1}$ KAW architects

2 Urban Economics group, Wageningen University \& Research

3 Department of Spatial Economics, Vrije Universiteit Amsterdam
} 
Tinbergen Institute is the graduate school and research institute in economics of Erasmus University Rotterdam, the University of Amsterdam and VU University Amsterdam.

Contact: discussionpapers@tinbergen.nl

More TI discussion papers can be downloaded at http://www.tinbergen.nl

Tinbergen Institute has two locations:

Tinbergen Institute Amsterdam

Gustav Mahlerplein 117

1082 MS Amsterdam

The Netherlands

Tel.: +31(0)205984580

Tinbergen Institute Rotterdam

Burg. Oudlaan 50

3062 PA Rotterdam

The Netherlands

Tel.: +31(0)10408 8900 


\title{
To join or not to join? The impact of social interactions on local participation decisions.
}

\begin{abstract}
This paper investigates how social interactions impact the decision to participate in one's local environment. Existing work often reports correlations between social interactions and local participation, but it is unclear what the causal direction of this relationship is. A key contribution of this paper is that we are able to estimate the causal effect of social interactions on the decision to participate by systematically varying social attributes in a choice experiment. Based on a largescale survey in one Dutch municipality we analyze 3894 choice observations of 435 respondents. Our sample includes respondents who currently participate and respondents who do not. We find that at the recruitment stage being asked by a friend or acquaintance significantly increases the chances to volunteer. We also find significant homophily effects in terms of age as well as for the characteristics of the group already participating. Financial incentives have significant negative impacts on the decision to participate.
\end{abstract}




\section{Introduction}

Participation is a key component of democracy and the social and political fabric of society (Acik, 2013; Fernandez and Garcia, 2008). This is in particular visible at the local level. People who are actively involved with their living environment can make their voice being heard and thereby have the potential to shape their local environment. This can influence local governmental policies as well as the (self-)organization of a social event or a local service (Vermeij and Gieling, 2016). In addition, participation is associated with wellbeing benefits. First of all, it provides activities and services to the local community. Secondly, volunteering and participating is known to lead to increased happiness and subjective wellbeing levels for the participants themselves (Borgonovi, 2008; Wallace and Pichler, 2009). However, the extent of civic and political activity varies widely across individuals leading to heterogeneous responses to policies that seek to foster participation. For example, earlier studies have revealed that higher educated tend to participate more and that young and older people are less likely to be active than middle-aged people (Bekkers, 2005; Broese van Groenou and Van Tilburg, 2012). Therefore not all residents are able to articulate their needs and wishes for their living environment or benefit from the earlier mentioned wellbeing gains to the same extent.

Our main aim is to gain more insight in the key determinants of the choice to participate in an additional activity, in particular in the role of social network and social interaction variables. Furthermore, we investigate whether the importance of these social network aspects vary with personal characteristics such as age, gender, health limitations and level of education.

In this study, we define participation as voluntary activities that are performed in the local community. These activities are (potentially) beneficial to the local community a person resides in. ${ }^{1}$ We take a broad perspective to participation by considering volunteering in clubs or associations, religious organizations or societal organizations; informal initiatives related to the physical or social living environment; and taking part in policy or decision making processes of the municipal government, often referred to as 'formal participation' (Dekker, 2007).

Whereas previous studies mostly focus on the characteristics and motivations of those who participate, we take a novel perspective by studying the individual choice to participate in an additional activity of a representative sample of residents, including those who currently do not participate.

Therefore, we use a discrete choice experiment to study the decision to take up an additional participation activity. In our choice experiment respondents are asked to choose between several

\footnotetext{
${ }^{1}$ In the literature several closely related and partly overlapping concepts are used for these type of activities, like (voluntary) participation, civic engagement, civic activity or volunteering (e.g. Ryan et al., 2005; Lewicka, 2005; Lee and Brudney, 2009).
} 
choice alternatives including the status quo of not participating in the additional activity. Each alternative is characterized by a set of attributes (characteristics) that is potentially relevant for the individual (see Louviere et al., 2000). An important assumption is that individuals choose the alternative which gives them the highest perceived value. Although this method is widely used in marketing and (transport) economics (see e.g. Louviere and Hensher, 1982) in sociology it is rather new (see also Liebe et al., 2016; Beyer and Liebe, 2015). To our knowledge there are only a few examples of researchers that took on this challenge (Buskens and Weesie, 2000; Kinghorn and Willis, 2008). This might be due to the difficulty of incorporating 'soft' social attributes in choice experiments.

In our attempt to include the "soft" social attributes as well, we add to the literature on discrete choice experiments by including two attributes referring to social interactions in the choice experiment. The first attribute captures the group composition of the group of people already participating in the activity. Here we include the characteristics gender and age, whether a person is known by the individual and uncertainty about others participating. People's personal networks tend to be homogeneous with regard to socio-demographic and many other characteristics. This is the result of the homophily principle; people tend to interact with others like themselves more often than with dissimilar people (McPherson et al., 2001). McPherson and Smith-Lovin (1987) make a distinction between induced homophily, produced by the group composition, and choice homophily, produced by individual choices. By including the gender and age composition of the group of people already taking part in the activity as an attribute in the experiment, we investigate to what extent choice-based homophily plays a role in participation preferences and in that way reinforces the homogeneity of local social networks. Our setup gives the possibility to investigate causal relationships between group composition and individual choices, because the social attributes are systematically varied in the choice experiment.

Besides the characteristics age and gender, we also investigate whether people prefer cooperating with people they already know. This allows us to study whether local participation is mainly a source for establishing new social ties and networks or for strengthening existing ones. When it appears that most people have a strong preference for cooperating with people they know, it can be concluded that the existence of local social networks is a prerequisite for local participation to develop.

The second social attribute is related to the recruitment. By systematically varying how a person is recruited, we can derive the relative importance of recruitment as a determinant of the choice to participate in an additional activity by directly comparing it with other choice determinants. In addition, we measure to what extent the strength of the tie with the recruiting person explains the choice to participate in an additional activity. 
We survey people who currently participate and people who do not participate, while existing research on participation mostly focuses on people who already participate. Our approach offers new insights in how to involve new people in participation activities to unlock new 'participation potential'. A better understanding of the determinants of the choice to participate in an additional activity can improve measures to motivate different groups of residents to participate, both by policy makers and organizations that depend on volunteers.

The set-up of the remainder of this article is as follows. First, we elaborate on the theoretical framework that lays the foundation for our empirical research. In the third Section we provide an overview of the methods and data used, including the set-up of the choice experiment. Section four, on behavioural modeling, describes the approach we take in the modeling of the choices of the residents, as well as the results. Finally, in Section six we discuss the results and draw conclusions.

\section{Theoretical Framework}

The choice to participate is studied in a wide range of disciplines, often in 'relative isolation' of each other (Bekkers, 2005). Psychologists tend to focus on the motivation to participate. Their focus on personality traits and the way people interpret themselves and their surroundings dismiss the constraints people perceive in terms of time or health (Wilson, 2012). The rational choice approach, mostly applied in the economics literature takes into account these constraints by assuming that individuals weigh the benefits and costs of an activity in their decision to volunteer (Ryan et al., 2005; Wilson, 2012). However, this approach is generally individualistic and lacks potential community interactions. Sociologists tend to focus more on resources and usually account for the wider social network of a person as a driver of civic engagement (Bekkers, 2005). Brady et al. (1995), in their seminal article on political participation, distinguish resources as time, money and civic skills in terms of communicational and organizational capacities. Furthermore, they stress the importance of motivation and recruitment. In other words, people participate if they are able to, if they want to, and if somebody asks them to. We argue, that personal characteristics, personal motivation, the characteristics of the volunteering activity as well as the social network of a person impact the choice to take on an additional volunteering task. Therefore, we extend the approach of Brady et al. (1995) who solely focus on political participation to a broader definition of participation.

According to van Til (1988) individuals who volunteer typically do so after a careful decision process. In our theoretical framework (see Figure 1), the choice process consists of three stages: 1) becoming aware of a task/activity; 2) the evaluation of the personal costs and benefits of joining an additional activity; and 3 ) the final decision to participate or not. The most complex stage is the evaluation. Whether a person is inclined to take on an additional activity depends on 
his/her personal characteristics, the characteristics of the activity and how the person has been recruited.

The remainder of this section will discuss the main factors of the evaluation stage with a particular focus on how social interaction and social networks play a role.

***Figure 1: Three phases within the participation choice process***

\section{Personal characteristics}

People participate if they want to and if they are able to. This means that both the motivation and resources play an important role (Brady et al., 1995).

\section{Motivation}

Earlier studies show that 'helping others' is in general an important motivation for volunteering (Clary et al., 1996). However, in addition to this pure altruistic motivation additional functional motives can be distinguished, such as learning new things; create or enhance professional career opportunities; protect/contribute to something one cares about; enhance self-esteem and/or personal growth; and to be socially active (Clary et al., 1996). These functional motives are likely to change during one's life span. Young people, for example, might want to learn new things, while older persons want to contribute to a greater good. At the same time, both groups appreciate to meet friends and new people to gain a sense of belonging (Ekerdt, 1986). This is often referred to as the 'relational motive' (Clary et al., 1996; Tschirhart et al., 2001; Prouteau, 2008).

Local participation depends on one's trust in other members of the community (Lee and Brudney, 2009). Individuals with high levels of social embeddedness (i.e. the degree of connection with the local community) are more likely to believe that other people will also volunteer, and that they will be able to share the benefits of others' volunteering. With high levels of trust, rational individuals are willing to volunteer at their personal cost because the expected probability of "shirking" or free-riding by other people is low. Therefore, people who feel socially embedded in their communities will perceive larger benefits of volunteering than those who do not and therefore will be more likely to volunteer (Lee and Brudney, 2009). In addition, social embeddedness can affect the motivation for voluntary participation through solidarity, i.e. the willingness to make commitments to members of a group. (Ryan et al., 2005; Tomeh, 1973). Bell (1998) suggest that both a solidarity of interests and a solidarity of sentiments is needed for collective action and volunteering. This means that both commitment and affection to others in the local community is important.

\section{RESOURCES}


According to Brady et al. (1995), important resources for participation are time to take part in activities and civic skills, i.e. the communicational and organizational skills that facilitate effective involvement. These skills are needed for instance to write letters, to organize, to join or chair meetings and to give speeches. Educational achievement is probably the most important resource for participation, as many studies have shown that more highly educated people more often participate (Huang et al., 2009, Bekkers, 2005, Lewicka, 2005; Wilson and Musick, 1998). In addition, energy, health and personal commitment are seen as important resources (De Rooij, 2012). Resources influence the decision to participate as they reduce the costs associated with participation. Resource-poor individuals are less likely to choose costly activities, such as working in community groups or demonstrating (De Rooij, 2012). From a rational choice perspective resources can be seen as "inputs that make it easier to face the demands of volunteering" (Wilson, 2000, p. 219). As the importance of a resource depends upon the demands of particular activity, resources can partly explain the choice for different forms of participation (Brady et al., 1995).

\section{Activity characteristics}

\section{TASK}

People are motivated if they can relate to the overall goal of the activity. For example, because they feel connected with the cause (social inclusiveness, sustainability, safety etc.) and/or with the community (association, neighbourhood, school etc.) and the activity targets. Furthermore, the duration of the activity, as well as the frequency and (overall) time investment are important factors. Some voluntary activities are rewarded by (small) financial reimbursements to account for expenditures made such as transportation, parking or printing. For some people, this can be an important incentive. However, several studies also show that when paying volunteers, they are less likely to join and in addition commit less hours to the activity (Frey and Goette, 1999; Cameronet al., 2001).

Overall, there is an increasing tendency for volunteers to comply to more flexible and projectbased type of activities (Willems and Walk, 2013). This holds in particular for younger persons and people with (young) families. In addition, different types of tasks appeal to different persons. This can be related to their (functional) motives, but also to life-cycle stage and resources. Persons with the functional motive to 'protect something one cares about' more often prefer a practical task, while a person with a 'career' motive more often prefers a leadership related task (Willems and Walk, 2013).

\section{SOCIAL INTERACTION}

Although the motivations for participating are widely studied, the relationship between participating and the characteristics of the activity, such as the overall goal and the type of tasks are less often taken into consideration (Willems and Walk, 2013). An exception is the work of 
Ryan et al. (2001) who show that potential volunteers for whom the social interaction is an important motive are more likely to join an environmental stewardship program, while potential volunteers whose motive is to learn new things are less inclined to join. Prouteau and Wolff (2008) show that for volunteers in culture, leisure and religious associations, the relational motive (doing something with others) is found to be important.

Furthermore, the size and characteristics of the social network of an individual are known to be positively correlated to different ways of participation (Paik \& Navarre-Jackson, 2010; Wilson \& Musick, 1998; Ryan et al., 2005; Vermeij and Gieling, 2016). For instance, Wilson and Musick (1998) found that the number of friends, the frequency of informal social interaction, the network density and the frequency of formal social interaction are positively related to the diversity of volunteering activities and the number of hours volunteered.

\section{Process characteristics}

\section{RECRUITMENT}

Being recruited is a critical determinant of volunteering or participation more in general (Paik \& Navarre-Jackson, 2010). For instance, Musick et al. (2000) show that being asked to volunteer increases the probability of volunteering by 45 percent. Knowing more people increases the chance of being asked to participate (Brady et al., 1995; Ryan et al., 2005). The number of associational ties, religious involvement and the diversity in social ties are shown to increase the probability of being asked to volunteer (Paik and Navarre-Jackson, 2010). However, recruitment is not random, for instance women, parents, higher educated people and people with a higher socio-economic status all have higher probabilities to be recruited (Paik and Navarre-Jackson, 2010; Freeman, 1997). Still, also when controlling for the effect of selectivity, being recruited increases the probability to volunteer considerably (Yoruk, 2007; Paik and Navarre-Jackson, 2010).

\section{Methods and data}

The method we use to study the decision to participate is a discrete choice experiment (DCE) (see Louviere et al., 2000). In choice experiments respondents choose between several alternatives, which in our case are potential new participation activities. Each alternative is characterized by a set of carefully selected attributes that are potentially relevant for the respondents. The attributes can take different levels or values, which are systematically varied. In this way the effect of each attribute on individual stated choices can be studied. When designing a choice experiment the objective is to create a choice task that resembles the real decision context as good as possible. In sociology applications of this method have been limited until now (exceptions 
are Buskens and Weesie, 2000; Liebe et al., 2016; Beyer and Liebe, 2015). The design of a choice experiment is comparable to that of a factorial survey, a method more often used in sociological studies (see Wallander, 2009; Graeff et al., 2014). The vignettes used in factorial surveys also consist of various dimensions which can have different levels or values which are systematically varied by the researcher. But whereas in a factorial survey respondents are asked to evaluate single situations, most often in the form of a rating task, in a choice experiment they are asked to choose one item from a set of alternatives.

\section{Data collection}

The data for this research were collected by means of an online survey among a stratified sample of residents of the Dutch municipality Utrechtse Heuvelrug, held in February and March 2017. The municipality (48 506 inhabitants in 2016) comprises seven villages, ranging in size from around 1200 inhabitants to around 18.000 inhabitants $^{2}$. The municipality is located near the urbanized, economic core of the Netherlands, the Randstad area.

The municipality provided us with a random sample drawn from the total population of the municipality aged 18 years or over. Because age is an important explanatory variable of participation, we used a stratified sample based on four age groups 18-25; 26-45; 46-65 and 65+ years old. This resulted in a total sample of 2035 residents.

The residents were invited to fill in the online questionnaire by means of a personal letter sent by mail, which contained a link to the questionnaire and a personal 4-digit code to $\log \mathrm{in}^{3}$. To assure the anonymity of the respondents we kept the files with addresses strictly separated from the response files. The expected duration of the total survey was 25 minutes. We provided incentives for completing the survey to increase the participation rate. We announced to allot three vouchers of 75 euro each, usable in many shops in the Netherlands. Furthermore, we donated 2 euros for each completed questionnaire to one of three local charities of choice.

After the first letter two reminders were sent. The last reminder was sent only to the youngest age group in the sample, as the response in this group was relatively low. In total, we collected 538 completed questionnaires, a response rate of 25 percent. ${ }^{4}$ Table 1 shows the descriptive statistics of the sample.

\footnotetext{
${ }^{2}$ The average address density is 771 addresses per square kilometer. In the Dutch context, following the classification of Statistics Netherlands, it can therefore be described as little urbanized.

${ }^{3}$ In the letter we also indicated the possibility to receive a paper and pencil version of the online questionnaire by mail. 24 people, mostly elderly, made use of this opportunity.

${ }^{4}$ We are aware of a possible response bias. However, Keeter et al. (2000), used an experiment to conclude that low response rates are not necessarily problematic for items relating to social integration and volunteer work.
} 
Table 1. Sample descriptives

\begin{tabular}{llll}
\hline \hline Gender & $\%$ & Age (mean: 56) & $\%$ \\
Male & 46 & $18-25$ & 8 \\
Female & 54 & $26-45$ & 20 \\
Health limitations & 29 & $46-65$ & 38 \\
Higher education & 56 & $65+$ & 34 \\
\hline
\end{tabular}

\section{Survey design}

To obtain meaningful results it is important to design the choice questions in such a way that they resemble real-life choices as much as possible (Hess and Rose, 2009). Therefore we conducted a series of semi-structured interviews and combined the results with input from the theoretical framework discussed in Section 2. We interviewed 12 residents who participate on the local level in different ways, as well as an alderman and three civil servants of the municipal government who are concerned with participation from a policy making perspective. This qualitative approach provided rich, in-depth information about the considerations that play a role in the decision to participate and the wording that respondents use when speaking about participation.

The online questionnaire was developed in Sawtooth SSIWeb (Sawtooth Software, 2008). After developing the questionnaire we conducted a pilot study with a group of 11 respondents, composed of different ages and education levels. This was very useful and resulted for instance in the decision to split the choice experiment into two experiments, discussed further below. In addition to the choice experiment, we included questions about several demographic, socioeconomic and social network characteristics.

\section{Choice experiment}

The part of the survey that contains the choice experiment starts with a short introduction. The respondents are asked to imagine that they are asked to participate in an additional activity. Following this, they face an example choice set of three activities and the opt-out alternative 'none of these activities' (see Figure 2). The respondents are instructed to choose the option they prefer most, given their current situation. It is explicitly mentioned that it does not matter whether they currently participate or not.

\section{***Figure 2. Example of a choice set in the online questionnaire***}

We are interested in eight different attributes (or characteristics) of the choice. However, during the pilot it appeared this made the choice task too complex. When a task is too complex, the risk appears that people only focus on a subset of the attributes, completely disregarding the others. Therefore the experiment was split into two parts with largely overlapping attributes, which are 
presented consecutively. By means of 'mouseovers' an additional explanation is offered for several attribute levels. An overview of the attributes and attribute levels used in the two choice experiments is presented in Table 2.

Table 2. Attributes and attribute levels used in the choice experiment

\begin{tabular}{|c|c|c|c|}
\hline Attributes & Exp. 1 & Exp. 2 & \multirow{2}{*}{$\begin{array}{l}\text { Attribute levels } \\
\text { Volunteering for an association }\end{array}$} \\
\hline \multirow[t]{4}{*}{ Type of activity } & \multirow[t]{4}{*}{$x$} & \multirow[t]{4}{*}{$x$} & \\
\hline & & & Social activity \\
\hline & & & Improving residential environment \\
\hline & & & Formal participation \\
\hline \multirow[t]{3}{*}{ Role } & \multirow[t]{3}{*}{$x$} & \multirow[t]{3}{*}{$x$} & Member of the board, organizer \\
\hline & & & Practical tasks \\
\hline & & & Participant \\
\hline \multirow[t]{4}{*}{ Time per month } & \multirow[t]{4}{*}{$\mathrm{x}$} & \multirow[t]{4}{*}{$\mathrm{x}$} & 1 hour \\
\hline & & & 4 hours \\
\hline & & & 8 hours \\
\hline & & & 32 hours \\
\hline \multirow[t]{5}{*}{ Period } & \multirow[t]{5}{*}{$\mathrm{X}$} & \multirow[t]{5}{*}{$\mathrm{X}$} & One-off \\
\hline & & & 3 months \\
\hline & & & 6 months \\
\hline & & & 1 year \\
\hline & & & 2 years \\
\hline \multirow[t]{5}{*}{ Financial compensation } & \multirow[t]{5}{*}{$\mathrm{x}$} & & 0 \\
\hline & & & $€ 3 \mathrm{p} / \mathrm{h}$ for you \\
\hline & & & $€ 7 \mathrm{p} / \mathrm{h}$ for you \\
\hline & & & $€ 3 \mathrm{p} / \mathrm{h}$ for the activity \\
\hline & & & $€ 7 \mathrm{p} / \mathrm{h}$ for the activity \\
\hline Contact person municipality & $\mathrm{X}$ & & Yes \\
\hline & & & No \\
\hline Who asks you & & $\mathrm{X}$ & Friend \\
\hline & & & Acquaintance \\
\hline & & & Somebody you do not know \\
\hline & & & General call \\
\hline Who else participates & & $\mathrm{x}$ & $\begin{array}{cl}\text { Composition of the group: } \\
-\quad \text { Whether you know a person } \\
-\quad \text { Age } \\
-\quad \text { Gender } \\
-\quad \text { Still unknown who will participate }\end{array}$ \\
\hline
\end{tabular}

\section{ATTRIBUTES}

The first attribute of the potential activities is the type of activity, which represents different forms of participating:

- volunteering for an association, defined as volunteering for an association in your place of residence of which you are a member or to which you feel connected in another way;

- social activity, such as an event, a party, an eating group, volunteering at the foodbank, activities with young or elderly people; 
- improving your residential environment, for example activities for a clean environment, for local (traffic) safety, for green, nature or landscape, or local facilities;

- formal participation, defined as participating in the development of policy and/or decision making of the municipality.

Role, time per month and period are characteristics of the activity itself. The role can either be member of the board, organizer; practical tasks; or participant. Time per month varies from 1 to 32 hours. Period refers to the length of the commitment and ranges from a one-off activity to 2 years.

Financial compensation and contact person municipality are policy attributes which could be directly influenced by policy makers. Because it is less common and perhaps even counterintuitive to receive compensation for participation, we made a distinction between personal compensation, and a compensation for the activity/association. The levels we included are 0,3 to 7 euros per hour.

Contact person at the municipality refers to the availability of a person at the municipality who offers support upon request when applying for licenses or subsidies or establishes links between residents with plans for their neighborhood or village.

Who asks you and who else participates are the two attributes referring to social interactions. Who asks you refers to recruitment and involves four levels: friend; acquaintance, defined as somebody whose name you know and with whom you have a small conversation once in a while; somebody you do not know; or a general call, for instance a general email to members of an association or an announcement in the local newspaper. Who else participates captures the characteristics of the other people participating in the activity. These other persons participating are described by their age, their gender and whether the other person is known to the respondent. We incorporated also the option that it is still unknown who is going to participate as well. We included this social attribute as a picture in the experiment (see Figure 2, and Appendix A for all 14 levels).

A design with all possible attribute-level combinations across all alternatives would be too large to present in a survey, and therefore a selection of choice sets is used. We used SSIWeb's balanced overlap method to generate a design with 250 choice experiment versions (Sawtooth Software, 2008). We used a generic design (with unlabeled alternatives) with a fixed order of presentation of the attributes to reduce the complexity of the task. 


\section{Behavioral modelling}

Each respondent made 9 choices; 1 fixed choice task and 2 experiments consisting of each 4 choices. Because experiments 1 and 2 have overlapping attributes, the choices can be analyzed using 1 behavioral model. In total we collected 3894 choice observations of 435 respondents. To evaluate these choices we estimate a random utility model where the perceived value of choice $t$ of respondent $n$ of alternative $j$ is given by:

$$
U_{j n t}=A S C_{j}+\beta_{n} X_{j n}+\lambda_{n} Z_{j}+\tau_{n} \Delta Z_{n j}+\varepsilon_{j n t},
$$

The random utility model was developed by McFadden (1973) and has been used extensively to develop descriptive models of choice behavior and use these models to make predictions about changes in behavior resulting from policy interventions. In the model, perceived value $U_{j n t}$ depends on the value of the vector of attributes of the activity $\left(X_{j n}\right)$, the characteristics of other people participating in the activity and those who ask you to participate $\left(Z_{j}\right)$, and the social 'distance' $\Delta Z_{n j}$ of individual $n$ to the other people participating in activity $j$. This homophily variable depends on the characteristics of person $n$ as well as on the characteristics of the other people participating in alternative $j$. The sensitivity to the attributes $X_{j n}$ is captured by the taste parameters $\beta_{n}$ which potentially can be a function of personal characteristics. When decisions are independent of the characteristics of the alternative, the taste parameters $\beta_{n}$ are equal to 0 , implying that a change in the attributes of an alternative will not lead to changes in the probability that an alternative is chosen. Furthermore, the perceived value depends on the intrinsic preference for the alternative $A S C_{j}$. This intrinsic preference captures the perceived value for other attributes than reported in the experiment. It captures the fact that independent from the characteristics of the activity some individuals simply do (not) like the idea of participating in another activity and can be interpreted as the inclination of the individual to participate in an activity due to factors not observed. For our application we estimate the intrinsic preference for participation in an additional activity compared to the alternative 'none of these activities'.

The noise term $\varepsilon_{j n t}$ captures the fact that not all reasons for the choices can be observed and that individuals can make errors in their evaluation of the alternatives. We assume that the noise term follows a Gumbel distribution with different scale parameters for the experiments (denoted by index $e=0,1,2)$. This allows for potentially different variances of the noise term $\varepsilon_{j n t}$. Another way of specifying this is to multiply the systematic utility of the alternatives with a factor $\exp \left(\theta_{e}\right)$. The abovementioned assumptions result in the following choice probability for the scaled multinomial logit (MNL) model (Fiebig et al., 2010): ${ }^{5}$

\footnotetext{
${ }^{5}$ Because of identification of the parameters, the scale has to be estimated relatively to the first (fixed) choice task, so we use the normalization $\theta_{1}=0$, and estimate $\theta_{2}$ and $\theta_{3}$. The scale parameters are exponentiated because they
} 


$$
\mathbb{P}_{j t n e}=\frac{\exp \left(\exp \left(\theta_{e}\right) \times\left(A S C_{j n}+\beta_{n} X_{j n}\right)\right)}{\sum_{k=1}^{J} \exp \left(\exp \left(\theta_{e}\right) \times\left(A S C_{k n}+\beta_{n} X_{k n}\right)\right)}
$$

The scaled MNL model allows for the fact that choice behavior can be more (or less) random in experiments 1 and 2 compared to the first fixed choice task $(e=0)$.

The scaled MNL model assumes that the noise terms are uncorrelated over a series of choices. To control for the fact that unobserved preferences $\varepsilon_{j n t}$ can be correlated over a sequence of choices we use a panel model, where we estimate the probability that a series of choices is made. This model assumes that preferences $A S C_{j n}$ and $\beta_{n}$ remain stable over the series of choices of an individual. The choice probability for a series of choices $t=1 \ldots T(n)$ of individual $n$ is given by:

$$
\widetilde{\mathbb{P}}_{n}=\prod_{t=1}^{T(n)} \prod_{j=1}^{J} \mathbb{P}_{j t n} y_{j t n},
$$

where $y_{j t n}$ equals 1 when alternative $j$ is chosen and 0 otherwise, $T(n)$ is the number of choices made by individual $n$, and $J$ the number of alternatives ( 4 in our case). This probability is a multiplication of the probabilities of the chosen alternatives, because $\mathbb{P}_{j t n}{ }^{y_{t n}}=1$ when the alternative is not chosen. Intuitively the probability $\widetilde{\mathbb{P}}_{n}$ is higher when probabilities of the chosen alternatives are closer to 1 .

Because we have a limited number of observations per individual we cannot estimate the probabilities at the individual level and therefore we have to pool the observations. However, preferences for participation can be very different for different individuals. This so-called preference heterogeneity can be due to observed characteristics of the individual or might be due to unobserved characteristics or reasons. Latent class (LC) models are well suited for the estimation of preference heterogeneity stemming from observed characteristics in the data as well as from unobserved sources. These models have been broadly applied in marketing and economics (Kamakura and Rusell, 1989; Swait, 1994; Oser et al. 2013; Dimitropoulos et al. 2016). The model enables the identification of groups with different preferences for participation and show the socio-demographic factors contributing to the likelihood that individuals belong to these groups. For our application it is assumed that there are two classes (indicated by index $c$ ) with distinct preferences $A S C_{c}$ and $\beta_{c}$ and scale parameters $\theta_{1 c}$ and $\theta_{2 c} \cdot{ }^{6}$ The model estimates

need to be positive and this allows for direct testing whether there are significant scale differences between the two experiments compared with the scale of the first task. When this is the case, the model reduces to the standard MNL model.

${ }^{6}$ We were not able to obtain stable results for the 3 class model. 
for each individual in the dataset the probability that an individual belongs to one of the classes using (the vector of) covariates $Z_{n}:{ }^{7}$

$$
p_{c n}=\frac{\exp \left(\gamma_{c} Z_{n}\right)}{1+\exp \left(\gamma_{c} Z_{n}\right)}
$$

Because covariates differ between individuals, each individual will obtain different estimated class membership probabilities. The estimation routine estimates the class preferences $\left(A S C_{c}\right.$ and $\left.\beta_{c}\right)$, the scale parameters $\theta_{1 c}$ and $\theta_{1 c}$, and the class membership coefficients $\left(\gamma_{c}\right)$ jointly, by maximizing the log-likelihood for the sample:

$$
L L=\ln \left[\prod_{n=1}^{N} \widetilde{\mathbb{P}}_{n}\right]=\sum_{n=1}^{N} \ln \left[\sum_{c=1}^{C} p_{c n}\left(\gamma_{c} ; Z_{n}\right) \widetilde{\mathbb{P}}_{n}\left(A S C_{c}, \beta_{c}, \theta_{2}, \theta_{3} ; X_{c n}, y_{n}\right)\right]
$$

For the estimation of the models we use the open source estimation package PYTHONBIOGEME (Bierlaire, 2016).

\footnotetext{
${ }^{7}$ As class membership probabilities have to add up to 1 , only $C-1$ group membership vectors $\gamma_{c}$ can be estimated, where $C$ is the number of classes (two for our application). For our application $C=2$, implying that we estimate one set of group membership parameters $\gamma_{1}$. We follow the convention to include only covariates in the class membership model and not in the class utility functions.
} 
Table 3. Estimation results.

\begin{tabular}{|c|c|c|c|c|c|c|c|}
\hline \multicolumn{2}{|c|}{ Variable description } & Variable & MNL & $\begin{array}{l}\text { LC basic: } \\
\text { class } 1\end{array}$ & $\begin{array}{l}\text { LC basic: } \\
\text { class } 2\end{array}$ & $\begin{array}{l}\text { LC extended: } \\
\text { class } 1\end{array}$ & $\begin{array}{l}\text { LC extended: } \\
\text { class } 2\end{array}$ \\
\hline \multicolumn{2}{|c|}{$\begin{array}{l}\text { Intrinsic preference for participation } \\
\text { reference=no participation }\end{array}$} & ASCP & $-0.7685^{* *}$ & $1.365^{* * *}$ & $-3.836 * * *$ & $1.402^{* * *}$ & $-3.995 * * *$ \\
\hline Recruitment & asked by acquintance & ^acqu & $-0.2474 * * *$ & $-0.528 * * *$ & 0.1057 & $-0.5431 * * *$ & 0.129 \\
\hline \multirow[t]{2}{*}{$\begin{array}{l}\text { reference=asked by } a \\
\text { friend }\end{array}$} & $\begin{array}{l}\text { asked by somebody you } \\
\text { do not know }\end{array}$ & ^sydnk & $-0.5263^{* * *}$ & $-0.9648 * * *$ & -0.3392 & $-1.012^{* * *}$ & -0.0693 \\
\hline & asked via general call & $\wedge \mathrm{gc}$ & $-0.5907 * * *$ & $-1.025^{* * *}$ & $-1.405^{*}$ & $-1.059 * * *$ & $-0.9917^{*}$ \\
\hline \multirow[t]{3}{*}{ Group composition } & $\begin{array}{l}\text { \# of unknown people } \\
\text { participating (incl. '?') }\end{array}$ & ^noupp & $0.148^{* * *}$ & $0.0984^{*}$ & $0.2659 * * *$ & 0.099* & $0.252 * * *$ \\
\hline & \# of '?' participating & ^nqmp & $-0.1976 * * *$ & $-0.1494 * * *$ & $-0.477^{* *}$ & $-0.1504^{* * *}$ & $-0.4024 * *$ \\
\hline & $\begin{array}{l}\text { expected \# of women } \\
\text { participating }\end{array}$ & ^nowp & $0.1088^{* * *}$ & 0.0381 & $0.2219 * *$ & 0.038 & $0.225^{* * *}$ \\
\hline \multirow[t]{3}{*}{ Homophily } & $\begin{array}{l}\text { average age distance } \\
\text { (linear) of respondent } \\
\text { to participants }\end{array}$ & Taged & $-0.0169 * * *$ & $-0.0114^{* *}$ & -0.0058 & $-0.0114 * *$ & -0.0027 \\
\hline & $\begin{array}{c}\text { average age distance } \\
\text { (squared) of respondent } \\
\text { to participants }\end{array}$ & Tagedsq & $-0.0004 * * *$ & $-0.0003^{* *}$ & -0.0006 & $-0.0003^{* *}$ & -0.0005 \\
\hline & $\begin{array}{c}\text { average gender } \\
\text { distance of respondent } \\
\text { to participants }\end{array}$ & Tgen & 0.0226 & -0.0467 & 0.054 & -0.0478 & 0.011 \\
\hline Activity: type & social activity & Bsa & -0.0972 & -0.1273 & -0.3678 & -0.1187 & $-0.4099 *$ \\
\hline \multirow[t]{2}{*}{$\begin{array}{l}\text { reference: volunteering } \\
\text { for an association }\end{array}$} & $\begin{array}{l}\text { improving residential } \\
\text { environment }\end{array}$ & Bire & -0.1095 & $-0.2052 * *$ & -0.2795 & $-0.2024 *$ & -0.302 \\
\hline & formal participation & Bfp & $-0.5869 * * *$ & $-0.866 * * *$ & $-0.8578 * * *$ & $-0.871 * * *$ & $-0.898 * * *$ \\
\hline Activity: role & practical tasks & Bpt & $0.2577^{* * *}$ & $0.4096 * * *$ & -0.2109 & $0.417^{* * *}$ & -0.086 \\
\hline $\begin{array}{l}\text { reference: member of } \\
\text { the board, organizer }\end{array}$ & participant & $\mathrm{Bp}$ & 0.0951 & 0.1292 & $0.7094^{* * *}$ & 0.124 & $0.696 * * *$ \\
\hline \multirow[t]{2}{*}{ Activity: commitment } & $\begin{array}{l}\text { period of commitment } \\
\text { (months) }\end{array}$ & Bpoc & $-0.0095^{* * *}$ & $-0.0137 * * *$ & -0.0194 & $-0.0142 * * *$ & -0.0149 \\
\hline & $\begin{array}{l}\text { time investment per } \\
\text { month (hours) }\end{array}$ & Btipm & $-0.0374 * * *$ & $-0.0584 * * *$ & -0.0215 & $-0.0593 * * *$ & $-0.0237^{*}$ \\
\hline \multirow[t]{4}{*}{$\begin{array}{l}\text { Policy attributes: } \\
\text { financial compensation }\end{array}$} & $\begin{array}{l}\text { for the activity } \\
\text { (euros per hour) }\end{array}$ & Bfcfa & -0.0147 & -0.0309 & 0.1551 & -0.0305 & 0.147 \\
\hline & for the activity equals 0 & $\beta f c f a 0$ & $0.573 * *$ & $0.6011^{*}$ & 1.325 & $0.613^{*}$ & 1.39 \\
\hline & $\begin{array}{c}\text { for yourself } \\
\text { (euros per hour) }\end{array}$ & Bfcfy & $-0.089 * * *$ & $-0.1251 * * *$ & 0.0044 & $-0.1252^{* * *}$ & 0.004 \\
\hline & for yourself equals 0 & $\beta f c f y 0$ & 0.1344 & 0.041 & 0.0812 & 0.052 & 0.177 \\
\hline $\begin{array}{l}\text { Policy attributes: } \\
\text { contact person } \\
\text { municipality }\end{array}$ & contact person available & Bcpm & 0.0292 & 0.1839 & -0.1077 & 0.189 & -0.1065 \\
\hline Scale parameters & $\begin{array}{l}\text { scale parameter } \\
\text { experiment } 1\end{array}$ & $\theta 1$ & -0.1607 & $-0.5561 * * *$ & 0.2158 & $-0.5658 * * *$ & 0.2 \\
\hline $\begin{array}{l}\text { reference: fixed choice } \\
\text { task }\end{array}$ & $\begin{array}{l}\text { scale parameter } \\
\text { experiment } 2\end{array}$ & $\theta 2$ & 0.1472 & -0.2082 & $0.4532^{* *}$ & -0.2288 & $0.516 * * *$ \\
\hline $\begin{array}{l}\text { Class membership } \\
\text { parameters }\end{array}$ & class constant & 「class & -- & 0 (fixed) & $-0.5894 * * *$ & 0 (fixed) & $0.565^{* *}$ \\
\hline \multirow[t]{7}{*}{ reference: class 1} & $\begin{array}{l}\text { age between } 18 \text { and } 25 \\
\text { (ref: } 65+\text { ) }\end{array}$ & vage18_25 & -- & -- & -- & -- & $-1.554 * * *$ \\
\hline & $\begin{array}{l}\text { age between } 26 \text { and } 45 \\
\text { (ref: } 65+\text { ) }\end{array}$ & page26_45 & -- & -- & -- & -- & $-1.796 * * *$ \\
\hline & $\begin{array}{l}\text { age between } 46 \text { and } 65 \\
\text { (ref: } 65+\text { ) }\end{array}$ & page46_65 & -- & -- & -- & -- & $-0.7284 * * *$ \\
\hline & highly educated & The & -- & -- & -- & -- & $-1.35 * * *$ \\
\hline & health limitations & 「hl & -- & -- & -- & -- & $0.701^{* * *}$ \\
\hline & $\begin{array}{l}\text { average class } \\
\text { probabilities }\end{array}$ & $\mathrm{p} 1$ & -- & 0.6432 & -- & 0.7102 & -- \\
\hline & $\mathrm{p} 2$ & & -- & 0.3568 & -- & 0.2898 & -- \\
\hline
\end{tabular}




\begin{tabular}{|c|c|c|c|c|}
\hline \multirow[t]{6}{*}{ Model characteristics } & null log-likelihood & $-5,398.23$ & $-5,398.23$ & -5398.23 \\
\hline & final log-likelihood & $-4,753.27$ & $-3,828.79$ & -3784.164 \\
\hline & \# of respondents & 435 & 435 & 435 \\
\hline & \# of choices & 3894 & 3894 & 3894 \\
\hline & \# of parameters & 24 & 49 & 54 \\
\hline & $\mathrm{SIC}$ & 9704.96 & 7955.27 & 7896.40 \\
\hline
\end{tabular}

Note: ${ }^{*}=$ significance at the $10 \%$ level; ${ }^{* *}=$ significance at the $5 \%$ level; ${ }^{* *}$ significance at the $1 \%$ level

\section{Discussion of the estimation results}

The estimation results of the multinomial logit (MNL) model and two versions of the latent class (LC) model are presented in Table 3.

We estimated the MNL model as a benchmark model (column 4 of table 3). Then we estimated a basic latent class model where class membership is only governed by a constant (columns 5 and 6 in Table 3). This model is then extended to a latent class model with the respondent covariates age (dummy variable with reference $65+$ ), high education ${ }^{8}$ and health limitations (columns 7 and 8 in Table 3). This results in different estimated class membership probabilities for each of the individuals in the dataset. The basic latent class model accounts for unobserved heterogeneity and shows a substantial improvement over the MNL model in terms of final loglikelihood. We use the Schwarz Information Criterion (SIC) to determine whether the additional parameters improve the fit of the model significantly as additional parameters always will improve model fit (Schwarz, 1978).

The marginal utilities themselves are difficult to meaningfully interpret as they are expressed in utility units. Therefore we compare the results of the extended latent class model to the coefficient for time per month needed for the activity (in hours) to get a better intuition for the order of magnitude of the estimated utility parameters. We first discuss the sample averages and then proceed to the discussion of the differences between the two latent classes.

\section{INTRINSIC PREFERENCE FOR PARTICIPATION}

The alternative specific constant for participation (ASCP) gives the intrinsic preference for participation in an additional activity compared to the status quo alternative (no additional participation). It captures other considerations then the variables listed in the experiment that influence the decision to participate and can be viewed as an indicator for motivation. The MNL model shows a significant negative coefficient for participating in an additional activity. For the basic and the extended latent class models we find strong heterogeneity: the first class shows a

\footnotetext{
${ }^{8}$ Or as some would say: theoretically educated.
} 
significant positive ASCP whereas for the second class it is strongly negative. The effect is substantial in a quantitative sense and positive when taking the average over the sample. ${ }^{9}$ For the extended latent class model, the average ASCP over the sample is comparable to an additional time contribution of about 32.1 hours per month. This is higher than the estimates from the MNL case, where we find a sample average that is equivalent to an additional time contribution of about 20.6 hours per month.

\section{SOCIAL ATTRIBUTES: RECRUITMENT}

To investigate the impact of recruitment variables, we created dummy variables for being asked by an acquaintance, being asked by somebody you do not know and being asked via a general call. The reference recruitment category is being asked by a friend. The MNL model shows a significant impact on the decision to participate for all these variables with decreasing values of the estimated coefficients $\left(\lambda_{\text {acqu }}, \lambda_{\text {sydnk }}\right.$ and $\left.\lambda_{g c}\right)$. When taking the average of the latent class estimates over the sample, being asked by an acquaintance $\left(\lambda_{\text {acqu }}\right)$ instead of by a friend is comparable in terms of perceived utility with adding 4.9 hours per month to the activity. The negative effect of being asked by somebody you do not know for the sample is comparable in terms of perceived utility to adding 13.0 hours per month to the activity. Being approached through a general call is comparable to an additional time contribution of 24.8 hours per month. These results imply that there are significant and quantitatively substantial social network impacts at the recruitment stage.

\section{SOCIAL ATTRIBUTES: GROUP COMPOSITION}

Next, we discuss whether the group composition of those already participating has an impact on the decision to participate in an additional activity. We include this variable in a continuous matter in order to be able to generalize the results to different group sizes. Significant effects are found for the number of unknown persons participating $\left(\lambda_{\text {noupp }}\right)$ (including question marks), the number of question marks participating $\left(\lambda_{\text {nqmp }}\right)$ and the number of women participating $\left(\lambda_{\text {nowp }}\right)$, although significance levels differ between the models and classes. Again, we report sample average values in comparison to the time coefficient for the extended latent class model. One additional unknown person in the group already participating has a positive effect on participation, presumably because people like to meet new people. This increase is comparable with reducing the time for the activity with 4.3 hours per month. However, the coefficient $\lambda_{n q m p}$

\footnotetext{
${ }^{9}$ We do so by first calculating the average of the ratio of the estimated parameter and the parameter estimate for time contribution per month $\left(\beta_{\text {tcpm }}\right)$. Then we calculate the estimated class membership probabilities for all respondents in the sample. With these class membership probabilities, we calculate the average ratio $\frac{A S C P}{\beta_{t c p m}}$ of the parameters for each respondent and then average over the sample. This corresponds to calculating the sample average class membership probabilities (as reported in the table) and multiplying these with the ratio of the estimated preference parameters.
} 
is negative implying that uncertainty about who else joins reduces the perceived value of participation. Having an additional question mark in the group is comparable with a contribution time increase of 6.7 hours per month. This suggests that there are strong uncertainty effects: moving from a question mark to an unknown person by communicating the characteristics of a person participating is comparable to a reduction of the time contribution of 11 hours per month $(4.3+6.7)$. The impact of the expected number of women participating has a positive impact on the decision to participate but is lower and equivalent to a reduction in time contribution of 3.2 hours per month per additional woman participating.

\section{SOCIAL ATTRIBUTES: HOMOPHILY}

Homophily is investigated by incorporating the relative effect of the group composition $\Delta Z_{n j}$, where we take into account the social distance of the person making a choice with the characteristics of other participants. Here we calculate the social distance for the variables gender and age, where for gender we assume a value of 0.5 for a question mark. For example, when one woman, 2 men and a question mark are already participating and the respondent of our survey is a woman, the social gender distance is 2.5 . If the respondent of our survey is a man, then the social distance is 1.5 . The estimated coefficient $\left(\tau_{g e n}\right)$ shows no significant impact of social gender distance for all models implying that respondents will not participate more if the group already participating is of the same gender as the person who is asked.

To investigate whether age distance impacts participation decisions, we incorporate the linear social age distance by subtracting the age of the respondent from the age of the people participating and average these over the number of known people participating. For example, when the ages of group members already participating are given by 25, 45 and 70 and the respondent has age 45 , the linear social age distance will be $((25-45)+(45-45)+(70-45))) / 3=5$ years. This is equivalent with calculating the average age of the participants and subtract the age of the respondent. ${ }^{10}$ The linear social age distance will be positive (negative) when the age of the respondent is lower (higher) than the average age of the participants. Significant impacts for the coefficient $\left(\tau_{\text {aged }}\right)$ are found in all models. The estimated coefficient is negative meaning that an increase in the linear social age distance reduces the likelihood to participate in an additional activity: respondents prefer to participate in a group of younger people if this would be the only effect. However, we also included the squared age distance by including the average squared age difference of the respondent to the participants. ${ }^{11}$ Here a significant negative effect is found, meaning that people prefer to participate in groups with participants with similar age. The two

\footnotetext{
10 Because: $\sum_{p=1}^{P} \frac{\left(A g e_{p}-A g e_{n}\right)}{P}=\sum_{p=1}^{P} \frac{A g e_{p}}{P}-A g e_{n}=\overline{A g e_{p}}-A g e_{n}$, where $P$ is the number of known participants, $A g e_{p}$ the age of participant $p, \mathrm{Age}_{n}$ the age of respondent $\mathrm{n}$ and $\overline{\mathrm{Age}_{\mathrm{p}}}$ the average age of the people participating.

${ }^{11}$ Here we use: $\sum_{p=1}^{P} \frac{\left(A g e_{p}-A g e_{n}\right)^{2}}{P}$, with the variables defined as in footnote 1 .
} 
impacts imply a trade-off: for a given age of the respondent the probability to participate increases when the average age of the group decreases. However, a decrease in the average group age will increase the squared social age distance. Using these two effects it is possible to derive the respondent age for which the likelihood of participation is highest given the age of those already participating. According to the model it is best for an existing group to ask somebody who is about 23 years older than the average group age, because respondents prefer to participate with younger people that are not too far off in terms of age distance. ${ }^{12}$

\section{ACTIVITY CHARACTERISTICS: TYPE, ROLE AND COMMITMENT}

For the type of activity, we created dummy variables (social activity, improving the residential environment and formal participation) with volunteering for an association as the reference category. For the type of activity, the coefficients $\beta_{s a}$ and $\beta_{\text {ire }}$ do show weakly significant impacts on the decision to participate (at the $10 \%$ level). Formal participation $\left(\beta_{f p}\right.$ ) has a significant negative impact on the choice to participate. The perceived resistance to formal participation at the sample level is substantial and comparable with an additional time contribution of about 21.4 hours per month.

To estimate the impact of the role a person has in the activity we created dummy variables for practical tasks $\left(\beta_{p t}\right)$ and participant $\left(\beta_{p}\right)$, with member of the board/organizer as the reference category. Significant positive effects are found implying that respondents prefer practical tasks and being a participant over being a member of the board/organizer. For practical tasks the effect is comparable to a reduction in time of 3.9 hours per month, whereas for being a participant the effect is comparable to a reduction of the time contribution of 10 hours per month. These effects are calculated at the sample level for the extended latent class models.

Significant effects are found for the coefficient for time contribution per month $\left(\beta_{c p m}\right)$. This shows that the probability to participate in an additional activity decreases when the time contribution increases.

For the period of commitment $\left(\beta_{\text {poc }}\right)$ we find significant negative impacts implying that the likelihood that respondents choose to participate in an additional activity decreases when the period of commitment increases. A one month increase in the period of commitment is comparable with an additional time contribution of 0.4 hours per month.

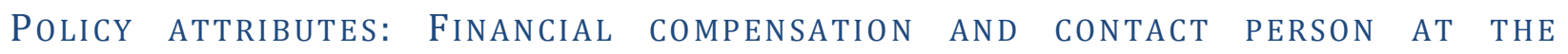
MUNICIPALITY

12 Because: $\frac{\partial U_{j n t}}{\partial A g e_{n}}=-\tau_{\text {aged }}+2 \tau_{\text {agedsq }}\left(\overline{A g e_{p}}-A g e_{n}\right)=0 \leftrightarrow A g e_{n}=\overline{A g e_{p}}+\frac{\tau_{\text {aged }}}{2 \tau_{\text {agedsq }}}=\overline{A g e_{p}}+\frac{\tau_{\text {aged }}}{2 \tau_{\text {agedsq }}}=\overline{A g e_{p}}+23.2$. Note that this calculation assumes 'all else equal'. 
Raising the financial compensation for the activity $\left(\beta_{f c f a}\right)$ has no significant effect on the decision to participate in all models. For financial compensation for the activity we tested for the zeroeffect $\left(\beta_{f c f a 0}\right)$ of compensation and find a significant positive effect. ${ }^{13}$ This shows a 'crowding out' effect when financial compensation for the activity is used: the likelihood to participate will decrease when financial compensation for the activity is offered. Respondents find financial compensation for the activity simply a bad idea: the impact is substantial and comparable to an additional time contribution of 24.4 hours per month. Such a zero-effect is not found for financial compensation for 'yourself' $\left(\beta_{f c f y}\right)$ as the coefficient is insignificant in all models. However, raising the financial compensation for the participant has a significant negative impact on the likelihood that people participate in an additional activity. An additional euro financial compensation is comparable with an increase in time of 2.8 hours. These results show that financial incentives will reduce the likelihood to participate in an additional activity regardless whether the money flows to the activity or to the respondent.

The availability of a contact person at the municipality does not affect the choice for a participation activity significantly as the coefficient $\beta_{c p m}$ is insignificant. Of course, this does not imply that the presence of a contact person has no added value for those people already participating: it only means that it will likely not impact the decision to participate.

\section{Class membership and differences between the classes}

The results show that there are substantial differences between class 1 and class 2 with the most striking difference being the negative ASCP for class 2. If respondents belong with high probability to class 2 their resistance to participate is likely to be high.

With the covariates, we can explain class membership at the individual level. We included the dummy variables for age, high education level $\left(\gamma_{h e}\right)$ and health limitations $\left(\gamma_{h l}\right)$ and found significant impacts and plausible signs. The group with age between 26 and 45 has the lowest probability to belong to the second class $\left(\gamma_{\text {age26_45 }}\right)$ and therefore they are more reluctant to take up additional participation activities. The reference group 65+ has the highest likelihood to belong to class 1 . Higher educated people are more likely to belong to class 1 and are more willing to participate in an additional activity, whereas people with health limitations are more likely to belong to class 2 likely because they are less able to participate in an additional activity.

\section{Discussion and Conclusions}

This paper developed a novel approach to the measurement of social interactions in choice experiments. This enables us to provide new evidence on the role of social interactions on stated

\footnotetext{
${ }^{13}$ See also: Shampanier et al. (2007) for a discussion on zero price effects in marketing. 
choices to participate in an additional activity. Our sample is representative and consists of people who already participate and those who do not. We found that social aspects such as recruitment, the composition of the group already participating and age-homophily are significantly impacting participation decisions.

Based on the results of the latent class model, we can roughly distinguish two groups of people ${ }^{14}$ : a group of people that is quite willing to take up a new participation activity, which we refer to as the 'yes, unless' group. And a group that is reluctant to participate in new activities, the 'no, except' group.

For the 'yes, unless' group, social networks play an important role in the choice to participate as they strongly prefer being asked by a friend or (to a lesser extent) by an acquaintance. With regard to the other people participating it is less important, as they do not mind whether they cooperate with persons they know or not. However, they prefer activities for which the other participants are known (reducing uncertainty) and with persons that are of similar age or younger.

The 'no, except' group is more difficult to influence as there are less significant choice determinants. The group composition is important for this group: they like to meet new people but want to know the characteristics of the people already participating. Furthermore, they prefer to participate in groups with older people. Another important finding is that they strongly prefer the role of participant, opposed to taking on a practical or organizational task. For this group, their current social network does not play an important role in the decision. However, this might be due to the characteristics of their current ties, as the experiment shows that they prefer to work with people they do not know so far.

Overall, we can conclude that recruitment is in particular important for people that are already interested in participation. The importance of the strength of the tie is a new finding in the literature. Furthermore, gender homophily does not impact participation choices significantly, but age homophily does: people prefer to participate with persons who are younger than they are. This can be problematic in areas with an ageing population, where volunteers are often really needed.

Not unexpected, we found a negative effect of the uncertainty of the people who already participate. People are less willing to join if it is not sure if there will be enough volunteers. This means it can be difficult to start new initiatives. However, meeting new and unknown people

\footnotetext{
14 Note that we use 'roughly' as all respondents belong to both groups with a probability depending on their covariates. Strictly speaking the classes can be viewed as two sets of preferences of one respondent.
} 
might also be exciting to a certain group of people who feel less connected with established groups and structures. More research into to this particular type of activity is needed.

An interesting finding from an economic point of view is that financial compensation can have a strong negative impact on the willingness to join. Most people volunteer out of an intrinsic motivation, which does not match with financial reimbursements. However, the municipality Utrechtse Heuvelrug is a relatively wealthy region. Repeating the experiment in a different setting might give different results.

Furthermore, it is clearly shown that residents do not like to be part of formal participation. Their preferences for this type of activity is significantly lower than for any other type of activity.

Our results underline that participation is more likely to flourish in areas where people know each other, where people are physically capable to participate, where education levels are high and where older people are active. As older people are less likely to participate in additional activities the participation potential in ageing areas is likely to decrease. One solution is to improve local interaction and to take a personal approach: recruit people through their friends and acquaintances and ask them for a role that suits them.

\section{Funding}

This work was supported by the Dutch national research association NWO [Aspasia grant 015.011.036]. 


\section{Appendix A Group characteristics in the experiment}

***Figure Appendix A about here*** 


\section{References}

Acik, N. (2013). Reducing the participation gap in civic engagement: Political consumerism in Europe. European Sociological Review, 29, 1309-1322.

Bekkers, R. (2005). Participation in voluntary associations: Relations with resources, personality and political values. Political Psychology, 26, 439-454.

Bell, M.M. (1998). The Dialogue of Solidarities, or Why the Lion Spared Androcles. Sociological Focus, 31, 181-99.

Beyer, H. and Liebe, U. (2015). Three experimental approaches to measure the social context dependence of prejudice communication and discriminatory behavior. Social Science Research, 49, 343-355.

Bierlaire, M. (2016). PythonBiogeme: a short introduction (No. EPFL-REPORT-221362).

Borgonovi, F. (2008). Doing well by doing good. The relationship between formal volunteering and self-reported health and happiness. Social Science \& Medicine, 66, 2321-2334.

Brady, H.E., Verba, S. Lehman Schlozman, K. (1995) Beyond SES: A resource model of political participation. American Political Science Review, 89, 271-294.

Broese van Groenou, M. and Van Tilburg, T. (2012). Six-year follow-up on volunteering in later life: A cohort comparison in the Netherlands. European Sociological Review, 28, 1-11.

Buskens, V. and Weesie, J. (2000). An experiment on the effects of embeddedness in trust situations: Buying a used car. Rationality and Society, 12, 227-253.

Cameron, J., Banko, K.M., and Pierce, W.D. (2001). Pervasive negative effects of rewards on intrinsic motivation: The myth continues. The Behavior Analyst, 24 (1), 1-44.

Clary, E.G., Snyder, M. and Stukas, A.A. (1996). Volunteers' motivations: Findings from a national survey. Nonprofit and Voluntary Sector Quarterly, 25, 485-505.

Dekker, K. (2007). Social Capital, Neighbourhood Attachment and Participation in Distressed Urban Areas. A Case Study in The Hague and Utrecht, the Netherlands, Housing Studies, 22 (3), 355-379.

De Rooij, E.A. (2012). Patterns of immigrant political participation: Explaining differences in types of political participation between immigrants and the majority population in Western Europe. European Sociological Review, 28, 455-481. 
Dimitropoulos, A., van Ommeren, J. N., Koster, P. and Rietveld, P. (2016). Not fully charged: Welfare effects of tax incentives for employer-provided electric cars. Journal of Environmental Economics and Management, 78, 1-19.

Ekerdt, D.J. (1986). The busy ethic: Moral continuity between work and retirement. The Gerontologist, 26 (3), 239-244.

Graeff, P., Sattler, S., Mehlkop, G. and Sauer, C. (2014). Incentives and inhibitors of abusing academic positions: Analysing university students' decisions about bribing academic staff. European Sociological Review, 30, 230-241.

Fernández, E.G. and García, F.J.F. (2008). Rethinking the sources of participation: A case study of Spain. European Sociological Review, 24, 479-493.

Fiebig, D. G., Keane, M. P., Louviere, J. and Wasi, N. (2010). The generalized multinomial logit model: accounting for scale and coefficient heterogeneity. Marketing Science, 29 (3), 393-421.

Freeman, R. B. (1997). Working for nothing: The supply of volunteer labor. Journal of Labor Economics, 15, S140-S166.

Frey, B. S. and Goette, L. (1999). Does pay motivate volunteers? Working paper, Institute for Empirical Research in Economics, 7.

Hess, S. and Rose, J.M. (2009). Some lessons in stated choice survey design. European Transport Conference Proceedings.

Huang, J., Van den Brink, H. M. and Groot, W. (2009). A meta-analysis of the effect of education on social capital. Economics of education review, 28 (4), 454-464.

Kamakura, W. A., \& Russell, G. (1989). A probabilistic choice model for market segmentation and elasticity structure. Journal of marketing research, 379-390.

Keeter, S., Miller, C., Kohut, A., Groves, R. M. and Presser, S. (2000). Consequences of reducing nonresponse on a national telephone survey. Public Opinion Quarterly, 64, 125-148.

Kinghorn, N. and Willis, K. (2008). Measuring Museum Visitor Preferences Towards Opportunities for Developing Social Capital: An Application of a Choice Experiment to the Discovery Museum. International Journal of Heritage Studies, 14, 555-527.

Lee, Y. and Brudney, J. (2009). Rational volunteering: A benefit-cost approach. International Journal of Sociology and Social Policy, 29 (9/10), 512-530. 
Lewicka, M. (2005). Ways to make people active: The role of place attachment, cultural capital, and neighbourhood ties. Journal of Environmental Psychology 25, 381-395.

Liebe, U., Hundeshagen, C, Beyer, H. and Von Cramon-Taubadel, S. (2016). Context effects and the temporal stability of stated preferences. Social Science Research 60, 135 - 147.

Louviere, J.J. and Hensher, D.A. (1982). On the design and analysis of simulated or allocation experiments in travel choice modelling. Transport Research Record 890, 11-17.

Louviere, J.J., Hensher, D.A. and Swait, J.D. (2000). Stated choice methods: Analysis and application. Cambridge University Press, Cambridge, UK.

McFadden, D. (1973) Conditional logit analysis of qualitative choice behavior, in P. Zarembka (Ed.), Frontiers in econometrics, Academic Press, New York (1973).

McPherson, M., Smith-Lovin, L. and Cook, J.M. (2001). Birds of a feather: Homophily in Social Networks. Annual Review of Sociology 27, 415-44.

McPherson, J.M., Smith-Lovin, L. (1987). Homophily in voluntary organizations: Status distance and the composition of face-to-face groups. American Sociological Review, 52: 370-379.

Musick, M. A., Wilson, J., \& Bynum, W. B., Jr. (2000). Race and formal volunteering: The differential effects of class and religion. Social Forces, 78, 1539-1570.

Oser, J., Hooghe, M., \& Marien, S. (2013). Is online participation distinct from offline participation? A latent class analysis of participation types and their stratification. Political Research Quarterly, 66(1), 91-101.

Paik, A. and Navarre-Jackson, L. (2010). Social networks, recruitment, and volunteering: Are social capital effects conditional on recruitment? Nonprofit and Voluntary Sector Quarterly, 20, 1-21.

Prouteau, L. and Wolff, F. (2008). On the relational motive for volunteer work. Journal of Economic Psychology 29, 314-335.

Ryan, R. L., Kaplan, R., and Grese, R. E. (2001). Predicting volunteer commitment in environmental stewardship programmes. Journal of Environmental Planning and Management, 44(5), 629-648.

Ryan, V.D., Agnitsch, K.A., Zhao, L. and Mulick, R. (2005). Making sense of voluntary participation: a theoretical synthesis. Rural Sociology 70, 287-313.

Sawtooth Software (2008). The CBC System for Choice Based Conjoint Analysis. CBC v6.0 Technical Paper. Sequim, WA.

Schwarz, G. (1978). Estimating the dimension of a model. The Annals of Statistics, 6 (2), 461-464. 
Shampanier, K., Nina, M. and Ariely, D. Zero as a special price: The true value of free products. Marketing science, 26 (6), 742-757.

Storm, I. (2015). Civic engagement in Britain: The role of religion and inclusive values. European Sociological Review, 31, 14-29.

Swait, J. (1994). A structural equation model of latent segmentation and product choice for crosssectional revealed preference choice data. Journal of retailing and consumer services, 1 (2), 7789.

Van Til, J. (1988). Mapping the third sector: Voluntarism in a changing social economy. New York: The Foundation Center.

Tomeh, A.K. (1973). Formal Voluntary Organizations: Participation, Correlates, and Interrelationships. Sociological Inquiry, 43, 89-122.

Tschirhart, M., Mesch, D. J., Perry, J. L., Miller, T. K. and Lee, G. (2001). Stipended volunteers: Their goals, experiences, satisfaction, and likelihood of future service. Nonprofit and Voluntary Sector Quarterly, 30, 422-443.

Wallace, C. and Pichler, F. (2009). More participation, happier society? A comparative study of civil society and the quality of life. Social Indicators Research, 93, 255-274.

Wallander, L. (2009). 25 years of factorial surveys in sociology: A review. Social Science Research $38,505-520$.

Willems, J., and Walk, M. (2013). Assigning volunteer tasks: The relation between task preferences and functional motives of youth volunteers. Children and Youth Services Review, 35(6), 1030-1040.

Wilson, J., Musick, M. (1998). The contribution of social resources to volunteering. Social science quarterly, 79, 799-814.

Wilson, J. (2000). Volunteering. Annual Review of Sociology, 26, 215-240.

Wilson, J (2012) Volunteerism research: A review essay. Nonprofit and Voluntary Sector Quarterly, 41, 176-212.

Vermeij, L. and Gieling, J. (2016). De dorpse doe-democratie. Lokaal burgerschap bekeken vanuit verschillende groepen dorpsbewoners. Den Haag: SCP. (In Dutch)

Yoruk, B. K. (2007). The power of asking in volunteering: Evidence from a matched sample. Economic Letters, 99, 79-84. 